\title{
Performance Studies Floating Free of Theatre. Richard Schechner and the Rise of an Open Interdisciplinary Field
}

\author{
Fabrizio Deriu \\ University of Teramo \\ fderiu@unite.it
}

\begin{abstract}
As Marvin Carlson points out, the term performance has recently developed "as a central metaphor and critical tool for a bewildering variety of studies, covering almost every aspect of human activity." While there is a tendency to stress their similarities and theoretical convergence, Performance Studies and Cultural Studies have different origins: the roots of Performance Studies are clearly located in theatre studies and practices. The essay outlines a short history of the rise of Performance Studies, focussing on Richard Schechner's work. According to him, a Performance Studies paradigm came to the fore in the mid-1950s, with books by Bateson, Austin, Goffman, Caillois and others. In the Sixties Schechner started to teach and was founder/director for influential theatre groups on the American avant-garde scene. When his interest shifted from theatre to performance and from aesthetics to social sciences, he found anthropology extremely useful because in ethnographies anthropologists treat the actual lived behaviours of people performatively. Schechner developed these assumptions and cooperated intensely with social scientists, in particular the anthropologist Victor Turner. In 1980 Schechner co-founded the Department of Performance Studies at NYU. Since then many academic institutions have started similar programs; Schechner's books have been translated into many languages; and worldwide a growing cohort of scholars have been attracted to this stimulating, inter-disciplinary, threshold-crossing approach.
\end{abstract}




\section{Introduction}

As Marvin Carlson points out in his Performance. A Critical Introduction, the term 'performance' has developed in recent years "as a central metaphor and critical tool for a bewildering variety of studies, covering almost every aspect of human activity. Performance discourse and its close theoretical partner, 'performativity', today dominate critical discourse not only in all manner of cultural studies, but also in business, economics, and technology" (2004: ix). However, while there is a tendency to stress their similarities and theoretical convergence, Performance Studies and Cultural Studies should not be confused. The roots of Performance Studies are clearly located in theatre studies and practices, with a strong emphasis on the interweaving of the two aspects.

The essay aims to outline a short history of the rise and spread of Performance Studies, focussing primarily on Richard Schechner's work. Internationally recognized as the pioneer in the field, Schechner himself gives an account of his path from theatre to performance in the Preface to the third edition of his Performance Theory (2003: ixxii).

\section{Origins of the performance studies paradigm}

According to Schechner, a performance studies paradigm came to the fore in the mid1950s, with such books and essays as Gregory Bateson's "A Theory of Play and Fantasy" (published in 1955, the same year as J. L. Austin's Harvard Lectures on the "performative", posthumously published in 1962), Erving Goffman's The Presentation of Self in Everyday Life (1959), and Albert Lord's The Singer of Tales (1960). Furthermore, Schechner recognizes in John Cage's ideas and works a very strong influence on his own thinking about performance. As for theatre people, above all he considered Jerzy Grotowsky, whom he met in 1967, as a fundamental inspiration source. Combined with his experience as a civil-rights and anti-Vietnam War activist, and a sometime participant-creator of happenings, he opened up a whole new range of research.

\section{The Sixties: from 'theatre' to 'performance'}

The Sixties was a very busy decade for Schechner. Soon after his Ph.D. graduation he started to teach at the Tulane University in New Orleans, and he was editor of the Tulane Drama Review (then renamed as TDR. The Drama Review) from 1962 to 1969. Under his direction TDR became, and is still today, one of the most important theatre journals in the USA and around the world. In addition, he was a founder and director of influential theatre groups on the American avant-garde scene: firstly the New Orleans Group and later, when he moved to New York in 1967, The Performance Group (TPG). 
Among TPG's productions, Dionysus in '69 (based on Euripides's The Bacchae) was a major and controversial breakthrough in the history of the New American Theatre.

It was in this period that Schechner's academic interest, as he says, "dramatically shifted from theatre to performance and from aesthetics to social sciences" (2003: ix). At the beginning Schechner was not sure what performance was, even if he knew it was more than what was appearing on the stages of New York, London, or Paris. Thus he found social and cultural anthropology extremely useful because in ethnographies and theoretical treatises anthropologists treated the actual lived behaviours of people performatively: "Taking a cue from Goffman's 1959 breakthrough book, I sensed that performances in the broad sense of that word were coexistent with the human condition. Goffman did not propose that 'all the world's a stage', a notion which implies a kind of falseness or put on. What Goffman meant was that people were always involved in roleplaying, in constructing and staging their multiple identities" (ix-x).

Schechner outlined for the first time his new perspective in an essay entitled "Approaches to Theory/Criticism", originally published in 1966. He starts by discussing the theory of the ritual origin of theatre in ancient Greece, supported by the so called Cambridge anthropologists such as Gilbert Murray, Jane Ellen Harrison and Francis Cornford, in order to make a different point: origin theories are irrelevant to understanding theatre, but ritual is not to be excluded from the study of the performative genres:

Ritual is one of the several activities related to theater. The others are play, games, sports, dance, and music. The relation among these I will explore is not vertical or originary - from any one to other(s) - but horizontal: what each autonomous genre shares with the others [...]. Together these seven comprise the public performance activities of humans. If one argues that theater is "later" or more "sophisticated" or "higher" on some evolutionary ladder and therefore must derive from one of the others, I reply that this makes sense only if we take fifth century BCE Greek theater (and its counterparts in other cultures) as the only legitimate theater. Anthropologists with good reason, argue otherwise, suggesting that theater - understood as the enactment of stories by players - exists in every known culture at all times, as do the other genres. These activities are primeval, there is no reason to hunt for "origins" or "derivations." There are only variations in form, the intermixing among genres, and these show no long-term evolution from "primitive" to "sophisticated" or "modern." Sometimes ritual, sports, and the aesthetic genres [...] are merged so that it is impossible to call the activity by any one limiting name. (Schechner, 1988b: 6)

These seven activities (later reduced to five, because theatre, dance and music merge into a single category, now labelled as 'performing arts') share some basic qualities: a special ordering of time and space; a special value attached to objects; nonproductivity in terms of goods (this does not mean that they have no economic value); a set of rules that govern the performers' behaviour. In any case, at this juncture Schechner still believed that performance was an extremely difficult concept to define: from one point of view (clearly stated by Goffman) performing is a mode of behaviour that may characterize 'any' activity (a 'quality' of actions, rather than a fenced-off 
genre); and simply framing an activity 'as' performance - viewing it as such - makes it into a performance (this was John Cage's opinion). However, theatre still remains the basic model:

I mean something much more limited: a performance is an activity done by an individual or group in presence of and for another individual or group. [...] in trying to manage the relationship between a general theory and its possible applications to various art forms, I thought it best to center my definition [...] on certain acknowledged qualities of live theater, the most stable being the audience-performer interaction. Even where audiences do not exist as such - some happenings, ritual, and play - the function of audience persists: part of the performing group watches - is meant to watch - other parts of the performing group; or, as in some ritual, the implied audience is God, or some transcendent Other(s). (30n)

\section{The Seventies: the Schechner-Turner connection}

During the Seventies, Schechner took these assumptions further, by means of both field research and theoretical studies (as well as his artistic practice). He published and/or edited several books and he cooperated intensely with social scientists. In particular the connection with Victor Turner, as we will see later, added to performance theory a very wide knowledge about ritual and what Turner called "social dramas."

On several occasions from 1968 to 1972 Schechner travelled outside the USA (especially in Latin America and in Asia) in order to attend to performances of many genres and traditions, and to carry out anthropological field researches. These trips, combined with intense studies in anthropology, social psychology, ethology and so on, were the basis of Schechner's belief that performance theory is a social science rather than a branch of aesthetics. As he wrote in Environmental Theater, a book about his association with TPG:

I reject aesthetics. [...] I am concerned with definitions, categories, and classifications because, like it or not, we carry within us cultural imprints. These are part of language, and the very process of thinking. There is a time when one must examine these imprints and accept or reject them. The imprint of what I call "orthodox theater" is narrow. I want to work to expand the definition of theater so that theater practice may be expanded, and vice-versa. (1973a: vii-viii)

A remarkable step in this trajectory was "Actuals. A Look into Performance Theory" (1970), an essay in which he related rituals in non-Western cultures to avantgarde performance in the Western theatrical scene, according to five features which are found both in avant-garde performances and in those of 'tribal people': "1) process, something happens here and now; 2) consequential, irremediable, and irrevocable acts, exchanges, or situations; 3) contest, something is at stake for the performers and often for the spectators; 4) initiation, a change in status for participants; 5) space is used concretely and organically" (1970: 51). At the core of the notion of 'actual' there is the 
idea that art is not a way of imitating reality or expressing states of mind but an event. The aesthetic principle of art viewed as an imitation of life (while life itself is merely a shadow of the ideal forms) - which began in the Western epistemological tradition with Plato - is thus overturned.

In 1973 Schechner edited a special issue of $T D R$ entirely dedicated to establishing in a systematic way a continuum between the social sciences and performance: "The shared basic assumption is that people in groups - whether of two, three or dozens - in some ways 'ritualize' their behaviors; 'present' themselves rather than just be" (1973b: 3 ). These patterns of presentation are susceptible to detailed study, and often the vocabulary of the social sciences has been adapted from the vocabulary of theatre (see, for example, the notion of 'role').

Also at this time Schechner read Charles Darwin's The Expressions of the Emotion in Man and Animals (1872), and this led him to the work of ethologists such as Julian Huxley, Konrad Lorenz, Irenaus Eibl-Eibesfeldt. Focus was currently on "body language" and a whole range of expressive behaviour different from the spoken or written word. Combined with the fascinating genres of dancing and music that he saw in Asia, these studies helped Schechner to connect ethology to sports, play to ritual, and art to role-playing. Here we come across a main feature of Schechner's understanding of what were to become Performance Studies: on one hand he uses the social sciences to better understand theatre and the performing arts, and on the other hand he is deeply interested in showing how the understanding of theatrical processes can enhance the understanding of the social processes and of everyday life.

Schechner's assumption is that the phenomena variously known as 'drama', 'theatre' or 'performance' occur among all the world's peoples and date as far back as historians, archaeologists, and anthropologists can go: "Evidence indicates that dancing, singing, wearing masks and/or costumes, impersonating other humans, animals, or supernaturals, acting out stories, presenting time 1 at time 2 , isolating and preparing special places and/or times for these presentations [...] are coexistent with the human condition" (1973c: 5). But in the Western world a very limited view prevailed: the narrowness of the Western 'orthodox' idea of theatre was essentially based on the supremacy of the written text, or the 'drama': "we in the west are accustomed to concentrating our attention on a specialized kind of script called drama. But the avantgarde in the west, and traditional theaters elsewhere, refocused attention on the doing aspects of scripts, and beyond script altogether to 'theater' and 'performance"" (7). He acknowledges the difficulty of using these loaded terms; nevertheless, rather than choose to invent new words he preferred to adopt precise definitions of the old ones:

To help this task I offer a model of concentric, overlapping circles; a set of four discs with the largest, and least strictly defined, "performance", on the bottom, each of the others resting on the one immediately larger than itself. The larger the size the more time and space covered and the broader the "idea area" occupied. Generally speaking, though not in every case, the larger disc contains all those smaller than itself. 


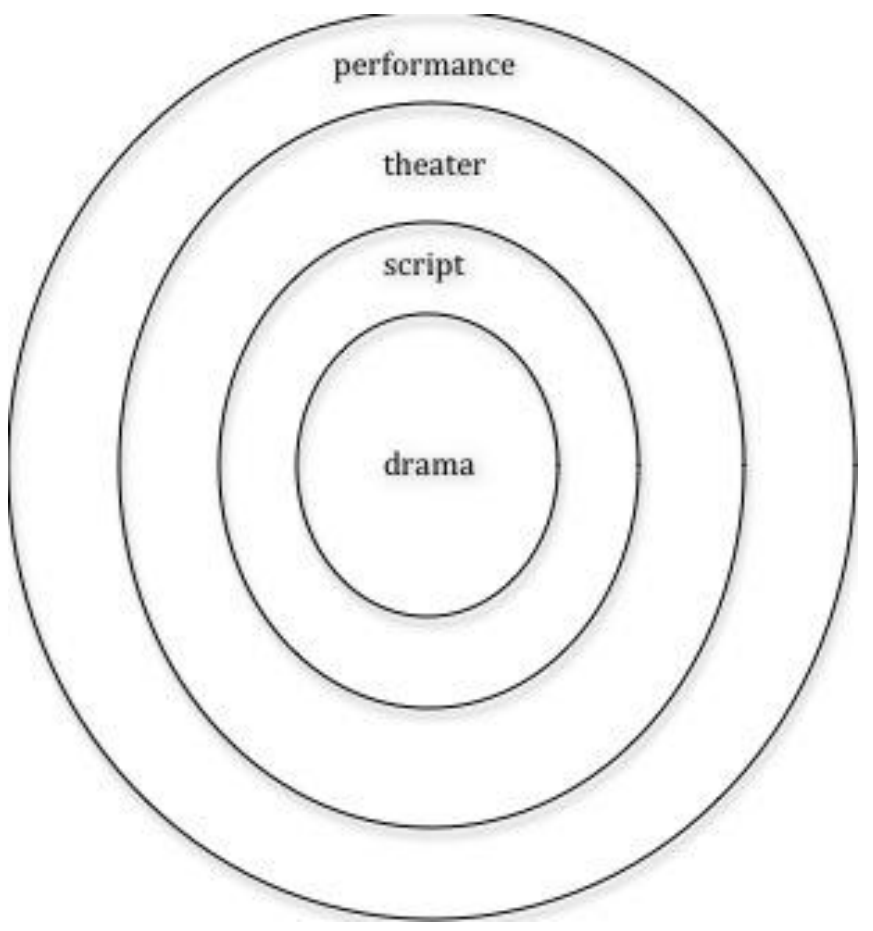

Drama: the smallest, most intense (heated up) circle. A written text, score, scenario, instruction, plan, or map. The drama can be taken from place to place or time to time independent of the person or people who carry it. These people may be just "messengers", even unable to read the drama, no less to comprehend or enact it.

Script: all that can be transmitted from time to time and place to place; the basic code of the events. The script is transmitted person to person, the transmitter is not a mere messenger. The transmitter of the script must know the script and be able to teach it to others. This teaching may be conscious or through empathetic, emphatic means.

Theater: the event enacted by a specific group of performers; what the performers actually do during production. The theater is concrete and immediate. Usually, the theater is the manifestation or representation of the drama and/or script.

Performance: the broadest, most ill-defined disc. The whole constellation of events, most of them passing unnoticed, that take place in/among both performers and audience from the time the first spectator enters the field of the performance - the precinct where the theater takes place - to the time the last spectator leaves.

The drama is the domain of the author, the composer, scenarist, shaman; the script is the domain of the teacher, guru, master; the theater is the domain of the performers; the performance is the domain of the audience. (8-9)

During the Seventies Schechner's ideas and practices were greatly nourished by his relationship with anthropologist Victor Turner. They knew each other's work but they met only in 1977. Turner died in 1983, and this six-year-long period of collaboration was extremely fruitful. Though Turner's contribution to Performance Studies is very extensive, it may be said to be mainly grounded in three sets of concepts: the first one is the 'social drama', the second is the three-phased description of the ritual process, the third is 'liminality' as the characteristic feature of the ritual process's second phase. 
According to Turner, social dramas are units of disharmonic social life, arising in conflict situations. They may occur on all levels of organization, from families to states; and have a typical four-stage structure of public action:

A social drama is initiated when the peaceful tenor of regular, norm-governed social life is interrupted by the breach of a rule controlling one of its salient relationships. This leads swiflty or slowly to a state of crisis, which, if not soon sealed off, may split the community into contending factions and coalitions. To prevent this, redressive means are taken by those who consider themselves or are considered the most legitimate or authoritative representatives of the relevant community. Redress usually involves ritualized action, whether legal (in formal or informal courts), religious (involving beliefs in the retributive action of powerful supernatural entities, and often involving an act of sacrifice), or military (for example, feuding, headhunting, or engaging in organized warfare). If the situation does not regress to crisis $[\ldots]$, the next phase of social drama comes into play, which involves alternative solutions to the problem. The first is reconciliation of the conflicting parties following judicial, ritual or military processes; the second consensual recognition of irremediable breach, usually followed by the spatial separation of the parties. Since social dramas suspend normal everyday role playing, they interrupt the flow of social life and force a group to take cognizance of its own behavior in relation to its own values, even to question at times the value of those values. In other words, dramas induce and contain reflexive process and generate cultural frames in which reflexivity can find a legitimate place. (Turner, 1982: 92)

What is important in a Performance Studies perspective is the connection between performances and the third stage of social dramas, redressive action. Turner regarded the social drama as the "experiential matrix" from which the many genres of cultural performance have been generated. The content of later genres (from oral and literary narrative to theatre and film) is provided by breach, crisis and reintegrative or divisive outcomes, while the redressive procedures provide the form: "As society complexifies, as the division of labor produces more and more specialized and professionalized modalities of sociocultural action, so do the modes of assigning meaning to social dramas multiply - but the drama remains to the last simple and ineradicable, a fact of everyone's social experience" (78).

As Schechner notes, while investigating ritual from an anthropological standpoint, Turner soon realized that social processes of any kind are performative. This is one of the reasons why he became deeply interested in theatre and performance and started a detailed exploration of the multiple relationship between ritual and theatre. The replication that occurs in the redressive phase, be it in the rational idiom of a judicial process or in the symbolic idiom of religious and/or artistic process, is of course a theatrical performance, a "formal restaging" of what happened: redress "furnishes a distanced replication and critique of the events leading up to and composing the "crisis"” (Turner, 1974: 41).

Turner's emerging understanding of the relationship between social drama and aesthetic drama relies on the three-phase structure of the ritual process, following the Belgian ethnologist Arnold Van Gennep. In a book entitled Les rites de passage (1909), 
he argues that in every human group, the passing from one life stage and 'status' (biological as birth and death, or social as puberty, marriage, social advancement, job specialization, and so on) is marked by symbolic actions and ceremonies. Van Gennep observed that these rites of passage move through three steps: the first consists of some kind of "separation" from the previous condition; the second is a period of "liminality" (from the Latin limen that means threshold); the third one is characterised by "reaggregation", in which the individual takes on the feature of the new condition. The key moment is the second one, in which what prevails is a liminal condition, that is a period of time when an individual is "betwixt and between" social categories or personal identities. According to Schechner, "[t]he liminal phase fascinated Turner because he recognized in it a possibility for ritual to be creative, to make new situations, identities and social realities" (2013: 66). What is peculiar to liminality is the fact that the attributes of "liminal personae are necessarily ambiguous, since this condition and these persons elude or slip through the network of classifications that normally locate states and positions in cultural space. Liminal entities are neither here nor there" (Turner, 1969: 95). This ambiguity and indeterminacy is culturally expressed by a rich variety of symbols and symbolic behaviours. As Turner himself argued, it is as though liminal people "are being reduced or ground down to a uniform condition, to be endowed with additional powers to enable them to cope with their new station in life" (95). In other words, people undergoing the ritual become temporarily "nothing', exposed to vulnerability but open to change; then they are inscribed with their new attributes and identities. Taking a cue from Turner's description of the liminal state, Schechner outlines the intrinsic affinity between the liminal personae and the condition of actors and performers. In particular, as he says, "the workshop-rehearsal phase of performance composition is analogous to the liminal phase of the ritual process" (2013: 66).

Whether at a social and collective level or at the individual level, Schechner and Turner shared the belief that performances deal with transformation - how people use performances to experiment with, act out and ratify change. As a result of this fruitful collaboration, Schechner noted an ever-increasing confluence of anthropology and theatre. In a 1983 essay entitled "Points of Contact between Anthropological and Theatrical Thought" he lists some points (and "there are likely to be more coming"): transformation in being or consciousness; state of intensity (i.e. the crossing of a threshold); complex interactions between audience and performer; a whole sequence of rule-governed behaviours prior to and after the main event on display (training, workshop, rehearsal, warm-ups, public performance, cool-down, aftermaths); transmission of performance knowledge (by means of embodied practices, because it belongs to oral tradition and it is different from simply "knowing the great dramatic texts"). 


\section{Restoration of behaviour}

In the second half of the Seventies, Schechner looked back to the period 1960-1975, when there was a burst of experimental energy in American theatre (as well as in European theatre). Directors, authors, actors and performers, designers, composers, visual artists, and managers generated a profusion of forms, spaces, social contexts: "In rooms, in theatres, in the streets, in the fields, in workplaces (factories, storefronts), in hospitals, prisons, in gathering places (railroad stations, laundromats), in galleries, in schools - theatre, live performance, literally was everywhere trying to do everything" (Schechner, 1981a: 48). At the end of the Seventies all that activity ceased. In a critical essay (quite ironically entitled "Decline and Fall of the American Avant-Garde"), Schechner investigated the reasons for such a decline: he argued that the collapse of the theatrical Avant-Garde occurred in parallel with the end of the belief in collective systems, the shortfall of social action, the incomprehension of the press, the lack of continuity and the shortage of financial resources. Despite the unhappy conditions, he did not stop his compelling research, but he decided to turn to a larger set of objects, looking for cultural expressions that in the Western world have the same function that rituals and ceremonies have in tribal and/or non-Western societies. Since the theatrical experimental Avant-Garde had undergone a disintegration, it was now time to find the traces of the theatre - its inner workings or basic mechanisms - in cultural manifestations other than the 'orthodox' theatre: in social rituals (religious, political, secular rituals), and especially in popular entertainment, both live and mediated (sports, movies, TV shows and news, theme parks, etc.).

As a result of this intense theoretical effort, Schechner conceived the notion of "restoration of behavior", one that is still considered the core for every definition of performance. Restored behaviour - as Carlson put it - is "any behaviour consciously separated from the person doing it - theatre and other role playing, trances, shamanism, rituals" (2004: 3). Schechner wrote a lot about "restored behavior" in several essays published between 1980 and 1983, most now collected in Between Theatre and Anthropology (1985). It is not easy to synthesize the multiple aspects of the notion. My choice here is to offer a long quote from the very first definition of the concept:

Restored behavior is living behavior treated as a film director treats a strip of film. These strips of behavior can be rearranged or reconstructed; they are independent of the causal systems (social, psychological, technological) that brought them into existence. They have a life of their own. The original "truth" or "source" of the behavior may be lost, ignored, or contradicted - even when this truth or source is apparently being honored and observed. How the strip of behavior was made, found, or developed may be unknown or concealed; elaborated; distorted by myth and tradition. Originating as a process, used in the process of rehearsal to make a new process, a performance, the strips of behavior are not themselves process but things, items, "materials." Restored behavior can be of long duration as in some dramas and rituals or of a short duration as in some gestures, dances, and mantras. Restored behavior is used in all kinds of performances from shamanism and exorcism to trance, from ritual to aesthetic dance 
and theater, from initiation rites to social dramas, from psychoanalysis to psychodrama and transactional analysis. The practitioners of all these arts, rites, and healings assume that some behaviors - organized sequence of events, scripted actions, known texts, scored movements - exist separate from the performers who "do" these behaviors. Because the behavior is separate from those who are behaving, the behavior can be stored, transmitted, manipulated, transformed. The performers get in touch with, recover, remember, or even invent these strips of behavior and then rebehave according to these strips, either by being absorbed into them (playing the role, going into trance) or existing side by side (Brecht's Verfremdungseffekt). The work of restoration is carried on in rehearsals and/or in the transmission of behavior from master to novice. [...] Restored behavior is symbolic and reflexive: not empty but loaded behavior multivocally broadcasting significances. These difficult terms express a single principle: the self can act in/as another; the social or transindividual self is a role or set of roles. Symbolic and reflexive behavior is the hardening into theater of social, religious, aesthetic, medical, and educational process. Performance means: never for the first time. It means: for the second to the $n$th time. Performance is "twice-behavedbehavior." (Schechner, 1985: 35-36)

\section{The Eighties: the dissemination decade and the "Broad Spectrum Approach"}

Since 1967 Schechner has been teaching at New York University in the former Drama Department. When he and his colleagues realized that they were no longer teaching only 'drama' and 'theatre', they decided to change the department's name. Thus, in 1980 Schechner and others co-founded the Department of Performance Studies at New York University; the first to be so labelled in the world. Some years later TDR added the subtitle Journal of Performance Studies to signal its more inclusive approach. The Eighties can be considered the decade of dissemination. Many other academic institutions, in the US and abroad, started programs in Performance Studies; Schechner's books were translated into many languages; a growing cohort of scholars from many countries and many different disciplines were attracted into this stimulating, inter-disciplinary, threshold-crossing approach.

The expansion of the field needed what Schechner called a "Broad Spectrum Approach" (cf. 1988a and 1989): treating performative behaviour, and not just the performing arts, as a subject for serious scholarly study. This means studying behaviour in ordinary, professional and social life 'as' performance:

How is performance used in politics, medicine, religion, popular entertainments, and ordinary face-to-face interactions? What are the similarities and differences between live and mediated performances? The various and complex relationships among players - spectators, performers, authors, and directors - can be pictured as a rectangle, a performance "quadrilogue." Studying the interactions, sometimes easy, sometimes tense, among the speakers in the quadrilogue is what performance studies people do. (Schechner, 1993: 21). 
Such a perspective assumes a very powerful and extended notion of performance. Schechner suggests that the complex phenomena of performance genres, performative behaviours and performance activities can be arranged into a continuum: play-gamessports-popular entertainments-performing arts-daily life-identity construction-ritual. But, he says, this straight-line schema is a limited representation, because each genre interacts with the others and the boundaries among them are not rigid. A threedimensional view would be better: "For example, though they stand at opposite ends [...], playing and ritualizing are closely related to each other. In some ways, they underlie all the rest as a foundation" (Schechner, 2013: 50). The understanding of ritual and play, as processes applying to a wide range of human activities (rather than as something confined to religion or child behaviour) is a crucial point in Performance Studies and a very important development in the social sciences.

\section{The Nineties: performance studies in a global world}

After a conference attended by more than five hundred people in New York in March 1995, under the title "Performance Studies: The Future of the Field", an international association (PSi: Performance Studies international) was created to promote communication and exchange among scholars and practitioners working in the field. Since then, PSi has held an annual conference, moving from the US to Europe, Australia, and Asia. Many other institutions, both academic and artistic, are becoming more and more interested in Performance Studies.

It can be certainly said that the Broad Spectrum Approach has been accountable for both the widespread academic reception of Performance Studies and a quite significant transformation of Schechner's original field of interest. The various chapters in his more recent books (cf. especially 1993 and 2004) examine various cultural performances as Schechner experienced them, but these performances "were often more social, political and religious than artistic. They were meant to effect and cause life, not reflect or express it. [...] Live performance increasingly happens not as art but as religious practice, political demonstration, popular entertainment, sports match, or intimate face-to-face encounter" (1993: 21).

Nevertheless, he has never stopped his artistic career. He has continued to direct theatre and performance productions in the US and abroad; and in 1992 he found ECA (East Coast Artists), "a professional ensemble dedicated to boldly reinventing classic texts, debuting radical international work, and challenging conventional notions of contemporary theater and performer training" (East Coast Artists, online publication). Furthermore, Schechner has developed an innovative psycho-physical performance technique, called "Rasaboxes", which offers performers a physical tool to access, express, and manage their feelings/emotions in performance: "Useful as performer training, rasaboxes also offers many other applications in various fields including therapy, business, and education. [It] integrates ancient theory with contemporary 
emotion research, studies in facial expression of emotion, neuroscience, and performance theory" (East Coast Artists, online publication; cf. also Schechner, 2001).

\section{The new millennium}

At present, there is a significant interest in Performance Studies worldwide which is not only limited to theatre scholars and practitioners. As Schnechner himself argues, the field is unsettled, open, diverse, and multiple in its methods, themes, subjects, arts, and persons - but in practice it has developed in a certain way. It is no coincidence that he has brought out a third edition of Performance Studies. An Introduction, originally published in 2002 (following a revised second edition in 2006), accompanied by a companion website, with resources for instructors and students.

As Tracy Davis argues in her introduction to The Cambridge Companion to Performance Studies, in the second half of the twentieth century there was first a 'linguistic turn' (emphasizing language's role in constructing perception), and then a 'cultural turn' ("tracking the everyday meaning of culture, and culture's formative effect on identities"). The twenty-first century seems to be the time for a "performative turn' (cf. Davis, 2008: 1-8). Based on intense interactions between scholarly and artistic activity, Performance Studies might indeed be considered as a new perspective in the epistemology of the social sciences and the humanities. As Schechner writes in his new, extensive introduction, whose words I will use as final remarks:

Performance Studies came into existence within, and as a response to, the radically changing intellectual and artistic circumstances of the last third of the twentieth century. As the twenty-first century unfolds, many people remain dissatisfied with the status quo. Equipped with ever more powerful means of finding and sharing information - the internet, cell phones, sophisticated computing - people are increasingly finding the world not a book to be read but a performance to participate in. [...] Performance Studies is an academic discipline designed to answer the need to deal with the changing circumstances of the "glocal" [...]. My goal is nothing less than making performance studies a method of analysis, a way to understand the world in its ceaseless becoming, and a necessary tool for living. (2013: 25, x)

\section{References}

Austin, John Langshaw (1962): How to Do Things with Words. Clarendon Press: Oxford.

Bateson, Gregory (1972) [1955]: “A Theory of Play and Fantasy”, in Id., Steps to an Ecology of Mind, Chandler Publishing Company, San Francisco.

Carlson, Marvin (2004, second edition): Performance. A Critical Introduction. London and New York: Routledge.

Darwin, Charles (1965) [1872]: The Expression of the Emotions in Man and Animals. Chicago: Chicago University Press. 
Davis, Tracy C. (2008): "Introduction: the Pirouette, Detour, Revolution, Deflection, Deviation, Tack, and Yaw of the Performative Turn", in Tracy Davis, ed., The Cambridge Companion to Performance Studies. Cambridge: Cambridge University Press, 1-8.

East Coast Artists (ECA): http://www.eastcoastartists.org (accessed 15 November 2013).

Gennep, Arnold van (1960) [1909]: The Rites of Passage. Chicago: Chicago University Press.

Goffman, Erving (1959): The Presentation of Self in Everyday Life. Garden City, NY: Doubleday.

Lord, Albert (1960): The Singer of Tales. Cambridge, MA: Harvard University Press.

Schechner, Richard (1966): "Approaches to Theory/Criticism." The Drama Review 10(4): 2053.

- (1973a): Environmental Theater. New York: Hawthorn Books.

_ (1973b): "Performance and the Social Science. Introduction." The Drama Review 17(3): 3-4.

(1973c): "Drama, Script, Theatre and Performance." The Drama Review 17(3): 5-36.

(1977): Essays on Performance Theory. London and New York: Routledge.

(1981a): "The Decline and Fall of the American Avant-Garde." Performing Art Journal 5(2): 48-63.

(1981b): "Restoration of Behaviour." Studies in Visual Communication 7(3): 2-45.

- (1983): "Points of Contact between Anthropological and Theatrical Thought." South Asian Anthropologist 4(1): 9-30.

(1985): Between Theatre and Anthropology. Philadelphia: University of Pennsylvania Press.

(1988a): "Performance Studies: The Broad Spectrum Approach." The Drama Review 32(3): 4-6.

(1988b, second edition): Performance Theory. Revised and Expanded Edition. London and New York: Routledge.

(1989): "PAJ Distorts the Broad Spectrum Approach." The Drama Review 33(2): 4-9.

(1993): The Future of Ritual. Writings on Culture and Performance. London and New York: Routledge.

(2001): "Rasaesthetics." The Drama Review 45(3): 27-49.

(2003) [1970]: “Actuals: A Look into Performance Theory", in Id., Performance Theory. London and New York: Routledge, 26-65.

(2003, third edition): Performance Theory. London and New York: Routledge.

(2004): Over, Under and Around. London: Seagull Books.

(2013, third edition): Performance Studies. An Introduction. London and New York: Routledge.

Turner, Victor (1969): The Ritual Process. Structure and Anti-structure. Chicago: Aldine Publishing Company.

(1974): Dramas, Fields and Metaphors. Ithaca: Cornell University Press.

(1982): From Ritual to Theatre. The Human Seriousness of Play. New York: PAJ Publications. 